\title{
Ações do poder público e a prática da umbanda, candomblé e congado: Reflexões sobre a construção de patrimônios culturais ${ }^{1}$
}

\author{
Mariana Ramos de Morais*
}

Resumo: Assim como ocorre no âmbito nacional, na capital mineira o poder público municipal trata a religiosidade afro-brasileira como cultura e, neste sentido, desenvolve ações que visam preservar o congado, a umbanda e o candomblé. Este trabalho dialoga com a discussão sobre o patrimônio cultural no Brasil, a fim de refletir sobre as ações da Prefeitura voltadas para essas manifestações religiosas em Belo Horizonte e a forma como esse patrimônio é construído por seus praticantes. Patrimônios culturais são entendidos aqui como elementos mediadores entre diversos domínios sociais e simbolicamente construídos, estabelecendo pontes e cercas entre categorias cruciais, tais como passado e presente.

Palavras-Chave: Religiosidade afro-brasileira, patrimônio cultural, Belo Horizonte

\begin{abstract}
The government of Belo Horizonte (capital of the state of Minas Gerais) treats Afro-Brazilian religiosity as culture and, in this sense, develops actions that aim to preserve the congado, the candomble and the umbanda. This paper dialogues with the discussion about cultural heritage in Brazil for reflect on the Belo Horizonte's government actions related to Afro-Brazilian religions and the way their followers construct that heritage. In this text, cultural heritage is conceived as a mediator between social and symbolic fields, making a connection between categories such as past and present.
\end{abstract}

Keywords: Afro-Brazilian religiosity, cultural heritage, Belo Horizonte

1 A primeira versão deste trabalho, que é fruto das reflexões iniciais acerca do tema que desenvolvo na minha pesquisa de doutorado, consta nos Anais do $34^{\circ}$ Encontro Anual da Anpocs, Caxambu (MG), 25-29 de outubro de 2010. Os comentários à primeira versão foram extremamente valiosos. Agradeço a Maria Celeste Mira (PUC-SP) e Edson Farias (UnB), coordenadores da Sessão Temática - Economia e Políticas do Simbólico, pelas contribuições.

* Doutoranda do Programa de Pós-Graduação em Ciências Sociais da PUC Minas

Latitude, Vol. 4, n², pp. 25-42, 2010

DOI: https://doi.org/10.28998/2179-5428.20100203 
Ações do poder público e a prática da umbanda, candomblé e congado: Reflexões sobre a construção de patrimônios culturais

\section{Introdução}

Em Belo Horizonte, a religiosidade afro-brasileira se faz presente em manifestações como o congado ${ }^{2}$, a umbanda ${ }^{3}$ e o candomblét. Manifestações que têm recebido apoio da Prefeitura, seja por meio de ações da Fundação Municipal de Cultura (FMC) ou da Coordenadoria de Promoção da Igualdade Racial (Cpir). Assim como ocorre no âmbito nacional, por meio da Fundação Cultural Palmares (FCP), órgão ligado ao Ministério da Cultura, e da Secretaria Especial de Políticas de Promoção da Igualdade Racial (Seppir), vinculada à Presidência da República, na capital mineira o poder público municipal trata a religiosidade afro-brasileira como cultura e, nesse sentido, desenvolve ações que visam preservar as citadas manifestações.

Há registros da existência do congado em Belo Horizonte desde antes da inauguração da cidade, no fim do século XIX. Já a presença inicial da umbanda e do candomblé remonta ao século XX, nas décadas de 1930 e 1960, respectivamente. Essas manifestações que, no passado, tinham majoritariamente participantes negros, na atualidade são praticadas por pessoas de diversas etnias, e o candomblé e a umbanda são consideradas religiões universais ${ }^{5}$ (PRANDI, 2005).

No trabalho de campo para a realização de minha dissertação de mestrado pude perceber que há uma articulação entre as três manifestações religiosas praticantes de candomblé que mantêm atividades de umbanda; congadeiros que têm cargos em terreiros de candomblé; umbandistas que abrigam guardas de congado em suas casas. Essa articulação pode ser considerada uma característica da religiosidade afro-brasileira: o sincretismo.

Ao analisar questões sobre o sincretismo no campo religioso brasileiro, Sanchis (2001) afirma que o mundo religioso de matriz africana no Brasil não constitui somente permanência, cópia ou repetição. $O$ tempo todo ele está sendo recriado, dinâmica e conflituosamente, partindo de um eixo complexo de representação identitária que pode levá-lo a uma reivindicação dos fundamentos de sua tradição ou a uma

2 As irmandades de devoção a Nossa Senhora do Rosário, em Minas Gerais, são conhecidas também como congado, congadas ou reinados. O culto aos santos negros e a Senhora do Rosário incorpora e (re)cria um repertório de laços de pertencimento, irmandade e familiaridade entre os participantes.

3 Religião formada no Rio de Janeiro, no início do século XX, marcada pelo encontro de elementos da religiosidade africana, católica, indígena e kardecista.

${ }^{4}$ Religião que cultua divindades africanas, que personificam aspectos da natureza ou fenômenos naturais, criada em meados do século XIX na Bahia e que hoje está presente com variações por todo o Brasil.

${ }_{5}^{5}$ Religiões universais têm praticantes de diversas origens étnicas, nacionais, geográficas, de classe e de cor. 
Mariana Ramos de Morais

assimilação das demais influências presentes no espaço religioso do Brasil. Em outros trabalhos (SANCHIS, 1995 e 1997), o autor também discute o sincretismo religioso brasileiro e demonstra como a umbanda e o candomblé são constituídos de forma híbrida, nos permitindo fazer um paralelo com a construção da identidade brasileira.

O sincretismo também é um traço característico da prática religiosa em Belo Horizonte. Conforme apontado por Cardoso (2004), em 2002, na capital mineira, chegou-se a uma média de 2,4 práticas religiosas por pessoa. Para o autor, esse número indica um intenso trânsito religioso, que aponta para uma grande tolerância com expressões religiosas diversas.

Observa-se, no entanto, que o discurso do poder público, no caso de Belo Horizonte, é construído, no que tange à preservação dessas manifestações, sobre a manutenção das tradições, sem considerar as mudanças que ocorreram ao longo do tempo. Nem mesmo a articulação entre as manifestações é considerada nas ações desenvolvidas pela Prefeitura para a identificação e a divulgação das práticas religiosas de matriz africana.

Neste trabalho, apresento reflexões sobre o discurso e as ações do poder público em Belo Horizonte e a forma como as manifestações da religiosidade afrobrasileira nessa cidade são construídas e mantidas pelos próprios participantes. Duas questões permeiam a discussão proposta: em que aspectos as ações desenvolvidas pela Prefeitura influenciam a prática dessas manifestações? E ainda: a preservação da cultura negra é uma preocupação daqueles que participam dos cultos de umbanda e candomblé e dos festejos do reinado?

O presente texto busca um diálogo com estudos sobre o patrimônio no Brasil para verificar se a forma como o poder público busca preservar as manifestações afrobrasileiras em Belo Horizonte está de acordo com a maneira como esse patrimônio é construído por seus praticantes. A discussão que proponho acerca da questão do patrimônio faz-se em um contexto metropolitano, que abarca todas as complexidades da sociedade contemporânea. Uma sociedade heterogênea que lida com "[...] as dificuldades e as limitações de uma ação pública responsável pela defesa e pela proteção de um patrimônio cuja escolha e definição implicam necessariamente arbítrio e, em algum nível, exercício de poder" (VELHO, 2006, p. 246). Conforme o autor, dentro do quadro heterogêneo e complexo dos grandes centros urbanos na contemporaneidade, a atividade religiosa, incluindo seus rituais e suas crenças, é fundamental para a construção e para a dinâmica das identidades.

\section{Religiosidade afro-brasileira em Belo Horizonte}

Dentre as manifestações religiosas afro-brasileiras hoje presentes em Belo Horizonte, o congado é a mais antiga. Registros apontam que antes mesmo da construção da capital de Minas, no então arraial do Curral del Rei, os negros louvavam Nossa Senhora do Rosário. Não há detalhes de como eram realizados os festejos, mas, em suas memórias sobre Belo Horizonte, Barreto (1995) relata que

Latitude, Vol. 4, n², pp. 25-42, 2010. 
Ações do poder público e a prática da umbanda, candomblé e congado: Reflexões sobre a construção de patrimônios culturais

[...] as festas religiosas principais eram: a da padroeira, a 15 de agosto; a do Divino, a de Santa Ifigênia, a de S. Sebastião, a de Santo Antônio e as da Semana Santa. [...] Na primeira dominga de outubro realiza-se o Reinado ou Reisado, a festa favorita dos pretos, os quais atroavam o arraial com seus adufes, tambores, sambucas, puítas e reco-recos, dançando em louvor a Nossa Senhora do Rosário. Nesse dia, pela manhã, havia missa cantada e, à tarde, efetuava-se a cerimônia de deposição dos reis velhos e eleição dos novos, para o ano seguinte. (BARRETO, 1995, p. 264)

Além da Igreja Matriz, dedicada a Nossa Senhora da Boa Viagem, existia no Curral del Rei uma capela em homenagem a Nossa Senhora do Rosário que, conforme Barreto (1995), não tinha beleza nem arte, sendo o referido templo "completamente desprovido de ornatos e alfaias, quase nada tinha de interessante", mas estava localizado em uma parte alta de onde se tinha um belo panorama do arraial (BARRETO, 1995, p. 257).

No congado estão presentes valores e saberes africanos em grande parte vinculados à cultura banta, cuja ritualística está centrada na homenagem a Nossa Senhora do Rosário, bem como à devoção a outros santos católicos e ao culto aos antepassados. Particularidades regionais e transformações ao longo do tempo levaram à adoção de outros termos - como congos, congadas e reinados - para se referir a essa prática religiosa, que também podem ter significados variados (LUCAS, 2002).

A Irmandade de Nossa Senhora do Rosário do Jatobá, situada na região do Barreiro, é a mais antiga irmandade que ainda mantém seus festejos em Belo Horizonte. Sabe-se, por meio da tradição oral, que no final do século XIX os negros se reuniam com guardas de Ibirité e de Mateus Leme, cidades próximas à região, para festividades dedicadas à santa, que ocorriam em Ibirité.

Nos festejos do congado, a presença de umbandistas e candomblecistas é comum e, no caso da umbanda, há terreiros que praticam a religião e mantêm guardas de congado. Um exemplo disso é o Centro Espírita São Sebastião, que tem o mais antigo estatuto em Belo Horizonte, datado de 1933, e é comandado por Dona Isabel Casimira das Dores Gasparino. Ela herdou o terreiro, bem como a Guarda de Moçambique Treze de Maio de Nossa Senhora do Rosário, de sua mãe, Dona Maria Casimira das Dores (MORAIS, 2010).

$\mathrm{Na}$ década de 1930, surgiram os primeiros terreiros de umbanda na cidade. Muitos começaram funcionando em um cômodo da casa do próprio médium e, à medida que a demanda por atendimento ia crescendo, outras pessoas passavam a fazer parte do corpo mediúnico. Em alguns casos, o médium mantinha uma relação com a religiosidade afro-brasileira já existente em outras cidades mineiras. Como capital do estado, Belo Horizonte sempre atraiu moradores de diferentes regiões, que 
Mariana Ramos de Morais

traziam seus costumes e crenças. Outros terreiros surgiam com forte influência da doutrina espírita kardecista, presente no Brasil desde o século XIX e que a partir da década de 1940 se popularizou, tendo como principal expoente o médium Chico Xavier, mineiro, nascido em Pedro Leopoldo, a 38 quilômetros de Belo Horizonte.

A relação da umbanda com outras práticas religiosas afro-brasileiras e com o kardecismo é própria da formação da religião umbandista. Na interpretação de Roger Bastide (1971), ela seria a continuidade de manifestações afro-brasileiras encontradas principalmente no Rio de Janeiro, denominadas macumbas, que em contato com a doutrina kardecista, introduzida no Brasil ainda no século XIX, passaram a ganhar outra roupagem. Àquela época, os praticantes dessa nascente religião não mais se restringiam aos negros. Os brancos participavam do novo culto e chegavam até mesmo a chefiá-lo. Para Cândido Procópio Ferreira de Camargo (1961), que pesquisou a umbanda em São Paulo, essa religião seria um continuum do kardecismo, podendo ter variadas gradações de influência da doutrina espírita. Os dirigentes do culto ora buscavam respaldo do kardecismo para se legitimar, ora se baseavam nos fundamentos africanos.

Em Belo Horizonte não há uniformidade no culto da umbanda, que tem como característica própria a mistura de práticas religiosas diversas. Assim, são encontrados terreiros em que o kardecismo é mais forte e outros mais "africanizados". Muitas vezes esse tipo está associado a outras manifestações religiosas, como o candomblé, uma característica que reflete a forma como este se formou na cidade. Os primeiros iniciados no culto aos orixás tinham ou frequentavam terreiros de umbanda e, por caminhos diferentes, começaram a buscar no candomblé outros conhecimentos sobre a religiosidade afro-brasileira. O Rio de Janeiro - que muito já havia influenciado o movimento umbandista mineiro - e a Bahia passaram a ser os principais destinos daqueles que buscavam a iniciação no candomblé. Na capital, os terreiros de candomblé foram abertos a partir da década de 1960, sendo o primeiro o Ilê Wopo Olojukan, dirigido por Carlos Olojukan, que veio da Bahia para Belo Horizonte em 1963. No entanto, em cidades do Norte do estado, como Pirapora e Montes Claros, já havia candomblé e, por isso, também eram destinos dos umbandistas que buscavam tornar-se filhos de santo. Mas não eram apenas os belo-horizontinos que iam ao encontro desse novo conhecimento religioso. Muitos pais e mães de santo passaram a aportar na capital, contribuindo para a conformação do candomblé na cidade.

A relação do candomblé com a umbanda sempre foi estreita em Belo Horizonte. Muitos umbandistas passaram a ter contato com o candomblé e aderiram à religião dos orixás. Alguns abandonaram a umbanda e outros optaram por trabalhar com os dois cultos. $\mathrm{O}$ fato de a umbanda ter precedido o candomblé em Belo Horizonte contribuiu para esse trânsito entre as manifestações. A interlocução entre a umbanda e o candomblé teve continuidade, não se limitando apenas ao momento de formação da religião dos orixás.

No inventário das manifestações afro-brasileiras em Belo Horizonte, realizado pela Prefeitura em 2004, dos 71 terreiros de candomblé pesquisados, 24 mantinham

Latitude, Vol. 4, n², pp. 25-42, 2010. 
Ações do poder público e a prática da umbanda, candomblé e congado: Reflexões sobre a construção de patrimônios culturais

também atividades da umbanda ou do omolocô ${ }^{6}$ (PONTES, 2006). Quarenta e sete terreiros praticavam apenas o candomblé, informação que deve ser relativizada, uma vez que é comum encontrar casas em que não há atendimento ao público com guias de umbanda, mas nas quais são realizadas homenagens anuais a essas entidades, o que caracteriza a manutenção de rituais umbandistas. A umbanda, que marcou o surgimento do candomblé em Belo Horizonte, ainda está presente em terreiros que cultuam as divindades africanas. Mas a passagem pela religião umbandista, antes comum aos iniciados no candomblé, nem sempre é verificada nos terreiros mais recentes.

No caso dos terreiros de umbanda, das 118 casas inventariadas, apenas 28 não têm contato com outra tradição e 13 declaram ter aproximação com congados. Esse último dado, relativo aos terreiros de umbanda com congados, pode não ser fidedigno. Durante pesquisa de campo para o levantamento de informações sobre a história do candomblé e da umbanda em Belo Horizonte 7 , pude verificar que existem componentes de guardas de congado que são responsáveis por terreiros de umbanda, além de constatar que iniciados de candomblé também mantêm ligações com as referidas manifestações. Estudando o congado em Belo Horizonte, Vilarino (2007) afirma que, ao ter contato com os grupos, encontrou dois tipos de comportamento quando era invocado nas conversas o tema sincretismo religioso: havia aqueles que assumiam a filiação a mais de uma manifestação religiosa e os que negavam qualquer aproximação. De acordo com o autor, muitos congadeiros, principalmente dirigentes de guardas, recusam-se a tratar dessa proximidade entre as manifestações.

Esse posicionamento de parte dos congadeiros também é encontrado no candomblé. Em pesquisa sobre a construção da identidade em terreiros de candomblé de Belo Horizonte (MORAIS, 2006), analisei dois grupos: o Grupo Espírita Estrela do Oriente, que é de origem banta e trabalha com umbanda e candomblé, e o Ilê Wopo Olojukan, de origem nagô, cujo pai de santo, Sidney Ferreira da Silva, é contrário ao sincretismo religioso. O posicionamento de Sidney é sustentado pelo discurso de religiosos e pesquisadores do candomblé que consideram que o culto de origem nagô é superior, por preservar melhor os traços da tradição africana ${ }^{8}$.

Dentro do processo de formação da umbanda, religião considerada genuinamente brasileira, há registro de movimentos que visavam desvincular o culto das práticas encontradas em manifestações de origem negra, apesar de a sua legitimação ter sido sustentada na religiosidade das três etnias que constituíram nossa

${ }^{6}$ Culto cuja linha ritual é originária de uma etnia banta. Ligado à umbanda, sobressaiu especialmente no Rio de Janeiro.

7 Essa pesquisa foi realizada por meio da Lei Municipal de Incentivo à Cultura de Belo Horizonte e resultou na publicação do livro "Nas teias do sagrado: registros da religiosidade afro-brasileira em Belo Horizonte" (MORAIS, 2010).

${ }^{8}$ Sobre a discussão acerca da busca da origem africana no candomblé, ver Capone (2004) e Dantas (1988). 
Mariana Ramos de Morais

identidade nacional (MAGNANI, 1986; NEGRÃO, 1996). Tais manifestações de origem negra ligavam a umbanda às praticas da macumba e a identificavam com a feitiçaria ou a magia negra. Essa ambiguidade entre a afirmação de sua origem e a fuga de estereótipos comportamentais associados aos negros contribuiu para que hoje encontremos terreiros de umbanda mais africanizados, em que elementos do candomblé se fazem presentes, como vestimenta, uso de atabaques, oferendas; e outros em que o kardecismo tem mais influência.

\section{Ações do poder público}

Na construção da história de Belo Horizonte, a participação dos negros, bem como suas tradições e heranças culturais, foi durante quase todo o século XX praticamente anulada nos registros oficiais. A Federação Espírita Umbandista do Estado de Minas Gerais ${ }^{9}$, fundada em 1957, teve um importante papel na divulgação da umbanda, num primeiro momento, e, posteriormente, do candomblé em Belo Horizonte. Na década de 1960, surgiram programas de rádio, discos e publicações voltadas para a religiosidade afro-brasileira. Entre os anos de 1962 e 1969, por exemplo, ia ao ar, aos domingos, de 7 h30 às 8 horas, na Rádio Jornal de Minas, o programa Ritmos da Umbanda, idealizado por Nelson Mateus Nogueira, que sempre foi colaborador da entidade, exercendo diversos cargos desde a sua fundação.

Nos anos 1970, esse movimento continuou com a publicação do jornal Tribuna de Xangô, informativo mantido pela federação. Em 1977, foi realizado um Simpósio de Umbanda em Belo Horizonte. Foi o primeiro evento voltado para o debate sobre essa religião na capital mineira, ao passo que o Rio de Janeiro já havia sediado três encontros. É importante ressaltar que, apesar da importância que a federação teve na institucionalização do universo umbandista na capital mineira, muitos terreiros funcionavam sem se vincular diretamente à entidade. Além disso, foram criadas outras entidades representativas dessas manifestações religiosas.

A partir da década de 1980, o poder público começou a atuar de forma mais direta com ações voltadas para a religiosidade afro-brasileira. O ano de 1982 pode ser considerado um dos marcos dessa mudança, com a inauguração do monumento a Iemanjá, na Lagoa da Pampulha, e da Praça 13 de Maio, no bairro Silveira. Assim, as religiões de matriz africana passaram a ser representadas simbolicamente na paisagem urbana, uma forma de o poder público reconhecer a presença dessas manifestações. A conquista desses dois espaços se deve, em grande parte, à atuação da Federação, que até então não mantinha uma relação com o Movimento Negro.

Em 21 de outubro de 1982, foi inaugurada a estátua de Iemanjá, em um dos principais pontos turísticos da capital mineira, a Lagoa da Pampulha, onde está o conjunto arquitetônico projetado por Oscar Niemeyer. O local escolhido para abrigar o

${ }^{9}$ A federação atualmente chama-se Associação de Umbanda e Candomblé do Estado de Minas Gerais.

Latitude, Vol. 4, n² 2, pp. 25-42, 2010. 
Ações do poder público e a prática da umbanda, candomblé e congado: Reflexões sobre a construção de patrimônios culturais

monumento dedicado à rainha do mar já fazia parte do domínio mítico das divindades na capital. Desde os anos 1950, os devotos realizavam os festejos a Iemanjá no mês de agosto. Inicialmente, a estátua ficava bem na margem da lagoa. Devido à facilidade de acesso ao monumento, este era alvo constante de vandalismo. Para tentar solucionar a questão, a Prefeitura de Belo Horizonte, em 2007, reformou e reestruturou o espaço. O artista plástico Jorge dos Anjos confeccionou o Portal de Iemanjá, uma estrutura de ferro com símbolos das divindades africanas. O portal emoldura a estátua, que foi reinstalada em um ponto da lagoa mais distante da margem.

No caso da Praça 13 de Maio, a situação foi um pouco diferente. Duas outras praças na cidade já haviam sido nomeadas com a data que marca o fim da escravidão no Brasil e, posteriormente, tiveram suas denominações modificadas, como consta no Decreto 4.325, publicado em 2 de outubro de 1982 pelo então prefeito Júlio Arnoldo Laender:

\footnotetext{
Considerando que o dia 13 de Maio faz lembrar um dos eventos mais importantes da história do Brasil, qual seja a abolição da escravatura;

Considerando que em Belo Horizonte já houve duas praças com o nome de 13 de Maio, vindo ambas a ter a sua denominação substituída;

Considerando que, para as comemorações pertinentes à data, é conveniente haver, na Cidade, um local apropriado;

Considerando, por fim, que a denominação em referência enriquece a toponímia urbana, sobre testemunhas, também, o apreço da população pela nossa história e cultura,

DECRETA:

Art. $1^{\circ}$ - Passa a denominar-se "Praça Treze de Maio" a praça formada pela confluência das Ruas João Lourival Dias, Biaggio Pollizzi, 2 e 4, no Bairro Silveira.
}

Ao contrário do destaque conferido à estátua de Iemanjá, localizada em um dos cenários mais visitados da cidade, a Praça 13 de Maio ainda é pouco conhecida entre os próprios belo-horizontinos. A praça não recebe visitação a não ser dos moradores locais e dos umbandistas, que a frequentam na data em que se comemora a abolição da escravatura. Além disso, o movimento umbandista reivindicava outro nome para o local, Praça do Preto-Velho, como consta em documento enviado por Nelson Mateus Nogueira, então candidato ao cargo de vereador pelo Partido Democrático Social (PDS), ao prefeito Júlio Laender, em 17 de agosto de 1982.

Ao analisar os espaços da religiosidade afro-brasileira em Belo Horizonte, Erisvaldo Pereira dos Santos (2008, p. 355) afirma que a não adoção do nome Praça do Preto-Velho e a escolha de uma data do calendário de fatos políticos da história brasileira produzem um "esvaziamento religioso do monumento". Entretanto, ele 
Mariana Ramos de Morais

pondera que, do ponto de vista do significado da conquista do novo espaço, no contexto da celebração do Dia do Preto-Velho, a praça representa uma forma de os umbandistas marcarem sua presença na cidade, rememorando a história da escravidão no Brasil, por meio do culto aos ancestrais.

Em 1986, foram publicadas duas leis municipais oficializando as festas de preto-velho (Lei 4.454) e Iemanjá (Lei 4.463). Nos dois textos, o então prefeito Sérgio Ferrara determina que a partir do ano seguinte a Prefeitura consignará recursos próprios para os festejos. Em 1987, uma nova norma que dispõe sobre as festas é sancionada. Dessa vez, a legislação determina que os eventos serão promovidos pela Federação Espírita Umbandista do Estado de Minas Gerais, com o apoio da Secretaria Municipal de Cultura e Turismo, indicando assim um envolvimento oficial do poder público.

Antes disso, porém, foi realizado, em 1984, o Seminário Tradição dos Orixás, Religião e Negritude, em Belo Horizonte. O evento foi fruto da parceria entre o Movimento Negro e o segmento religioso de matriz africana, que até então, como afirma Erisvaldo Pereira dos Santos (2008), não tinham atuação conjunta. O autor aponta que foi a partir da década de 1980 que, progressivamente, o segmento religioso de matriz africana começou a contar com o apoio e a mobilização do Movimento Negro de Belo Horizonte. Esse último passou a identificar nas comunidades religiosas afro-brasileiras um locus de resistência da cultura negra. Foi também um desdobramento da II Conferência da Tradição dos Orixás e Cultura, ocorrida em 1983, em Salvador, com a participação de militantes do Movimento Negro mineiro. Apesar de o seminário ter mobilizado lideranças políticas e religiosas, o autor aponta que não resultou no compromisso de tornar público os anais, com as reflexões e as medidas assumidas na ocasião.

Naquela época, uma das organizações de movimento social negro, denominada Luz Negra, afirmou uma tese fundamental na aproximação e no apoio que já referimos: "não há possibilidade de existência de movimento negro, sem que os grupos mantenham estreito vínculo com as instituições - mães da negritude - assim consideradas as Comunidades -Terreiros da Tradição dos Orixás e da Ancestralidade $[\ldots]^{\prime \prime 10}$. De forma categórica, essa tese se contrapôs aos discursos ideológicos que, fundamentados no materialismo dialético do marxismo, produziam como efeito o afastamento dos militantes dessas comunidades, em função da crítica às experiências religiosas. (SANTOS, 2008, p. 245)

10 FRANCISCO, Dalmir. Movimento negro, cidadania e estado. In: POMPERMAYER, Malori José (Org.) Movimentos sociais em Minas Gerais. Belo Horizonte, UFMG, 1987. p. 271., citado por Santos (2008).

Latitude, Vol. 4, n², pp. 25-42, 2010. 
Ações do poder público e a prática da umbanda, candomblé e congado: Reflexões sobre a construção de patrimônios culturais

Para Santos (2008), o seminário contribuiu para consolidar a aproximação de intelectuais que começavam a investigar o campo religioso de matriz africana em Belo Horizonte, que até então não havia sido objeto de pesquisas mais sistematizadas. Ressalta-se também o fato de militantes do Movimento Negro começarem a se iniciar no candomblé após o seminário, já na década de 1990. Assim, o discurso da negritude passou a fazer referência ao candomblé, bem como às demais manifestações religiosas afro-brasileiras. Essa aproximação do Movimento Negro em Belo Horizonte com as práticas religiosas segue a mesma orientação do que ocorria na Bahia, como aponta Jocélio Teles do Santos (2005) ao analisar as ressignificações dos símbolos afrobrasileiros tanto pelo poder público quanto pelos movimentos negros.

Ainda seguindo as experiências baianas, o Movimento Negro na capital mineira vai se articular para viabilizar o tombamento de dois espaços representativos da cultura afro-brasileira: um terreiro de candomblé e uma da irmandade de Nossa Senhora do Rosário ${ }^{11}$. Essa articulação inscreve-se em um contexto político mais geral: a vitória da Frente BH-Popular, liderada pelo Partido dos Trabalhadores, na campanha eleitoral para prefeito de 1992.

A partir da década de 1990, a Prefeitura de Belo Horizonte passa a realizar um trabalho de identificação, reconhecimento e divulgação das manifestações religiosas de matriz africana, iniciando com o processo de tombamento da Irmandade de Nossa Senhora do Rosário do Vale do Jatobá e do terreiro de candomblé Ilê Wopo Olojukan, em 1995, durante o primeiro Festival de Arte Negra (FAN), evento promovido pelo município, na ocasião do tricentenário de Zumbi dos Palmares ${ }^{12}$. Com o objetivo de discutir questões relacionadas à exclusão social da população negra e para integrar de forma mais sistemática a comunidade negra nos discursos identitários construídos pela Prefeitura, o FAN reuniu artistas e estudiosos da África e do Brasil para a realização de shows, oficinas, mostras de artes plásticas e cinema, conferências e seminários. Entre as atividades do festival, destacou-se a eleição de duas comunidades negras para se tornarem oficialmente patrimônio cultural do município, no caso, a Irmandade de Nossa Senhora do Rosário do Jatobá e o Ilê Wopo Olojukan. Os tombamentos foram realizados baseando-se em uma proposta que visava a inserção do elemento negro na construção da identidade oficial da cidade. Como a Irmandade do Jatobá é o congado mais antigo e o terreiro de Olojukan o primeiro candomblé da cidade, eles foram escolhidos para serem preservados.

Em 2004, como dito anteriormente, foi feito o inventário dos grupos de tradições afro-brasileiras na capital mineira, também organizado pela Prefeitura. De acordo com o levantamento, em Belo Horizonte existem 33 irmandades de Nossa Senhora do Rosário, 118 terreiros de umbanda e 71 terreiros de candomblé. Esse

${ }^{11}$ Em 1984, o Instituto do Patrimônio Histórico e Artístico Nacional (Iphan) havia tombado o terreiro de candomblé Casa Branca. Sobre esse tombamento, ver Velho (2006).

12 Sobre o processo de tombamento, ver Lott (2005). 
Mariana Ramos de Morais

trabalho resultou na publicação do livro Heranças do Tempo: tradições afro-brasileiras em Belo Horizonte (BELO HORIZONTE, 2006), e ainda está em curso a elaboração de documentários sobre as manifestações religiosas já citadas, sendo que o filme Salve Maria - Memória da religiosidade afro-brasileira em Belo Horizonte: Reinados Negros e Irmandades do Rosário, sobre o congado, foi finalizado.

O texto introdutório do livro ressalta a intenção da Prefeitura de registrar manifestações da cultura popular que poderiam "desaparecer":

O maior mérito deste inventário, além da investigação documental, é recuperar a auto-estima dos grupos detentores de conhecimentos tradicionais que habitam em Belo Horizonte, resgatar seus saberes e fazeres, promover seu patrimônio histórico e cultural, através de sua memória coletiva. (BELO HORIZONTE, 2006, p.8)

Ao propor uma recuperação da "auto-estima dos grupos detentores de conhecimentos tradicionais" e o resgate de "seus saberes e fazeres", a Prefeitura trabalha cada manifestação isoladamente, investiga os congados, a umbanda e o candomblé sem levar em conta as articulações entre essas manifestações realizadas por seus praticantes. No material já produzido pela Prefeitura, a aproximação ou sobreposição de manifestações é apresentada quantitativamente, mas não é realizada uma análise qualitativa desse dado.

Como demonstrado acima, tanto na literatura sobre o congado, o candomblé e a umbanda quanto em observações de campo, são identificados posicionamentos contrários a uma mistura entre essas manifestações religiosas - em sua maioria, no discurso dos responsáveis/dirigentes dessas manifestações. No entanto, percebe-se que os fiéis transitam entre elas sem questionar a "mistura", o que nos faz pensar que a preocupação com a "pureza" surge preponderantemente no discurso dos dirigentes ${ }^{13}$.

Prandi (2008) afirma que quando se discute a cultura brasileira é preciso considerar a presença de elementos religiosos de origem africana. De acordo com ele, esse fato faz com que a própria religiosidade afro-brasileira seja entendida como cultura e assim tratada também pelo Estado. O autor aponta que a Fundação Cultural Palmares, órgão público de um Estado laico, garante recursos e meios para a manutenção, restauração patrimonial e proteção institucional de religiões afro-

13 Valho-me aqui da discussão proposta por Dantas (1988) sobre o modelo "nagô puro" no candomblé, baseada na discussão de Mary Douglas (1976), que entende que a idéia de pureza é muitas vezes empregada como uma analogia para expressar a ordem social. Dessa forma, considerar um candomblé mais puro que o outro, de acordo com Dantas, não é somente uma forma de classificar ou marcar diferenças entre os terreiros. É também uma maneira de marcar um lugar para si e para os outros no conjunto do esquema de forças simbólicas da sociedade.

Latitude, Vol. 4, n², pp. 25-42, 2010. 
Ações do poder público e a prática da umbanda, candomblé e congado: Reflexões sobre a construção de patrimônios culturais

brasileiras, por considerá-las "uma espécie de celeiro que abastece a cultura brasileira" (PRANDI, 2008, p.165)..$^{14}$

Desde a década de 1960, entretanto, essas religiões deixaram de ser étnicas para se transformar em universais, isto é, abertas a seguidores de todas as origens étnicas, nacionais, geográficas, de classe e de cor. São hoje religiões de adesão individual, descoladas das antigas bases populacionais de origem africana, que se expandem por todo o Brasil e chegam a outros países da América, como Uruguai e Argentina, e da Europa. (PRANDI, 2008, p.165)

Além do apoio da Fundação Cultural Palmares, no âmbito federal, a Secretaria Especial de Políticas de Promoção da Igualdade Racial (Seppir) também trabalha para a manutenção da religiosidade afro-brasileira. A Seppir tem como missão estabelecer iniciativas contra as desigualdades raciais no país, sendo que a maioria de seus projetos é voltada para a cultura negra, provavelmente pelo fato de a Secretaria ter sido criada como um reconhecimento das lutas históricas do Movimento Negro Brasileiro ${ }^{15}$

Na Prefeitura de Belo Horizonte, a Coordenadoria de Promoção da Igualdade Racial tem atuado em consonância com o governo federal e, nesse sentido, lançou, no ano passado, o Plano Municipal de Promoção da Igualdade Racial ${ }^{16}$. No eixo "Cultura afro-brasileira", um dos objetivos do município é o tombamento de bens móveis e imóveis objetivando a preservação dos espaços socioculturais afrodescendentes. Outra ação é o "permanente apoio às religiões de matriz africana e às irmandades e guardas de congadeiros, por meio da realização de oficinas regionais bi-anuais e um encontro municipal também bi-anual" (BELO HORIZONTE, 2009, p.19).

Diante dessas ações, questiono em que aspectos as ações desenvolvidas pela Prefeitura influenciam a prática dessas manifestações. Como já apontado por Lott (2005), em pesquisa sobre o tombamento da Irmandade de Nossa Senhora do Rosário do Vale do Jatobá, a comunidade estava interessada, inicialmente, na isenção de impostos, e nem todos os seus integrantes tinham a compreensão do significado do tombamento do imóvel.

${ }^{14}$ Conforme relata Leonel (2009), em 2005, a Irmandade de Nossa Senhora do Rosário, em Divinópolis (MG), coroou o então Ministro da Cultura, Gilberto Gil, como Rei Congo, por ocasião da restituição do terreno e da capela do Rosário às irmandades daquele município.

${ }^{15}$ Sobre as políticas públicas de promoção da igualdade racial ver Theodoro (2008) e Jaccoud (2009).

${ }^{16}$ Coordenadoria de Promoção da Igualdade Racial é a nova denominação da Coordenadoria Municipal de Assuntos da Comunidade Negra, criada em 2005. A mudança foi regulamentada com a publicação do decreto 14.132, em 27 de setembro de 2010, no Diário Oficial do Município. 
Mariana Ramos de Morais

No caso do tombamento do terreiro de candomblé Ilê Wopo Olojukan, a proposta de construção de uma avenida impulsionou o processo. A Prefeitura de Belo Horizonte tinha o projeto de abrir uma avenida que dava para os fundos do terreiro. Mas, para que a via fosse construída, uma parte do terreno de mais de 2 mil metros quadrados da casa de candomblé teria de ser desapropriada. Isto significaria perda de espaço destinado ao culto aos orixás. Na mesma época, teve início um movimento pela preservação do local, durante o já citado Festival de Arte Negra (FAN). Com a proteção do município, o terreiro conseguiu evitar que a construção da avenida afetasse a área destinada ao culto (LOTT, 2005).

A inscrição do imóvel no livro de tombo não apenas garantiu a preservação do terreno onde está localizado o candomblé, como trouxe legitimidade para o pai de santo Sidney Ferreira da Silva, atual dirigente do Ilê Wopo Olojukan. Ele não era reconhecido por grande parte do povo de santo em Belo Horizonte pelo fato de ter herdado o terreiro do fundador, o pai de santo Carlos Olojukan, que faleceu dois anos após o tombamento. Sidney era neto de santo dele, enquanto o natural dentro dos preceitos da religião seria que um filho de santo de Seu Carlos, como também era conhecido, herdasse o trono.

No início, Sidney precisou enfrentar a resistência dos filhos de santo da casa, pois a maioria não aceitava que um neto de santo de Olojukan passasse a reger o axé. Para tentar impedir que Sidney assumisse o comando da casa, alguns filhos de santo reuniram-se e foram à Secretaria Municipal de Cultura pedir que o unicípio interviesse, já que o terreiro era tombado. Sidney tomou posse em 17 de junho de 1999, após cumprir os rituais e os preceitos devido ao falecimento de Olojukan, e continua no comando do terreiro, a despeito das resistências (MORAIS, 2006).

\section{Construindo patrimônios}

É por meio da tradição que os dirigentes de manifestações religiosas afrobrasileiras ganham legitimidade, que pode ser conquistada através de contatos com grupos mais antigos, pelo número de pessoas que frequentam as atividades do grupo ou pelo poder público, que pode lhes garantir a proteção material e imaterial. A tradição constitui-se em suporte para a construção da identidade, seja individual ou coletiva. Ao analisar a constante busca pelas origens no candomblé, Capone (2004, p.255) se pergunta: "O que é, enfim, uma tradição?". Com essa questão, a autora discute a procura das origens perdidas no candomblé e as implicações da busca por uma tradição, muitas vezes reinventada.

Para fazer sua análise, ela se apoia na discussão sobre tradição desenvolvida por Hobsbawm e Ranger (1984). Os autores destacam que as tradições inventadas seriam uma resposta a novas situações, sob a forma de referências a situações anteriores. A busca por restabelecer a tradição ocorre em situações em que esta é vista como um ideal perdido, em face às mudanças proporcionadas pelo avanço da modernidade. Quando, em uma sociedade, ainda existem pessoas que conservam a 
Ações do poder público e a prática da umbanda, candomblé e congado: Reflexões sobre a construção de patrimônios culturais

tradição, não é necessário recuperá-la nem mesmo inventá-la. Assim, a perda da tradição seria o motor da busca das origens, que tem sempre como objetivo a reconstrução de um estado original.

Acredito que as ações da Prefeitura de Belo Horizonte voltadas para a religiosidade afro-brasileira podem motivar a busca por um estado original por parte dos responsáveis pelas manifestações. Talvez isso ocorra porque o movimento em direção ao passado, com freqüência, torna-se um instrumento político para legitimar a posição ocupada pelo grupo, que reivindica sua tradição no seio de uma sociedade hierarquizada. A afirmação de sua tradição é uma forma de se distinguir dos outros, aqueles que não têm mais identidade definida (CAPONE, 2004, p.255, 256).

Os estudos contemporâneos sobre a tradição apontam que ela interage com o processo de construção da identidade. Dessa forma, a tradição não pode ser vista apenas como um simples reservatório de idéias ou elementos culturais. A tradição tem caráter interacional, e seu uso estratégico na afirmação da identidade do grupo que a reclama contribui para demonstrar que não é algo dado, mas reinventado continuamente, sempre agregando novas significações (FARIAS, 2004).

No caso deste trabalho, a própria religiosidade afro-brasileira, considerada aqui como patrimônio cultural, é reinventada continuamente pelos diferentes atores sociais que se articulam em torno dela, seja o poder público, o Movimento Negro ou os próprios devotos. Partindo do pressuposto, com Gonçalves, de que os patrimônios são "fatos sociais totais", seguindo a noção de Marcel Mauss, podemos reconhecer que qualquer objeto ou modo de vida pode tornar-se "patrimônio cultural", cujo processo de transformação (social e simbólica) é operado por diversos agentes e instituições em determinado tempo e espaço (GONÇALVES, 1996 e 2005).

Desde a década de 1980, o patrimônio, um tema antes tratado por historiadores e arquitetos, passou a ser focalizado pelas Ciências Sociais. Ao longo desses anos, as discussões, que antes se limitavam aos órgãos ligados ao patrimônio, tiveram um movimento crescente nas universidades e, atualmente, novos debates nacionais e internacionais vêm colocando o tema na ordem do dia das políticas públicas no Brasil e no exterior. Nesse contexto, os cientistas sociais vêm sendo convocados diante de mudanças significativas nas formulações de políticas do patrimônio, principalmente com o fomento ao chamado patrimônio intangível (ABREU, 2005).

É possível encontrar formas de patrimônio cultural no mundo contemporâneo fortemente relacionadas com a experiência, como, por exemplo, as festas religiosas populares, se consideradas do ponto de vista do devoto e de suas relações de troca com determinadas divindades. Para Gonçalves (2005), essa dimensão está em permanente tensão com a classificação do patrimônio cultural desenvolvida pelas agências de Estado, que é parcialmente assumida pelos devotos.

Ainda de acordo com Gonçalves (2005), os patrimônios culturais seriam entendidos mais adequadamente se situados como elementos mediadores entre diversos domínios social e simbolicamente construídos, estabelecendo pontes e cercas 
Mariana Ramos de Morais

entre categorias cruciais, tais como passado e presente, deuses e homens. $\mathrm{O}$ autor aponta que nas análises dos modernos discursos do patrimônio cultural, tem sido enfatizado o seu caráter "construído" ou "inventado". Cada grupo construiria no presente o seu patrimônio, objetivando a articulação e a expressão de sua identidade e sua memória, ponto decisivo para um entendimento sociológico da categoria patrimônio.

No entanto, Gonçalves afirma que há situações em que determinados bens culturais, classificados por uma determinada agência do Estado como patrimônio, não encontram respaldo ou reconhecimento junto a setores da população. Essa experiência de rejeição enfatiza que um patrimônio não depende apenas da vontade e decisão políticas de uma agência de Estado, tampouco de uma atividade consciente e deliberada de indivíduos ou grupos. Faz-se necessário que ele encontre "ressonância" junto a seu público ${ }^{17}$.

Acredito que as ações da Prefeitura de Belo Horizonte, muitas vezes impulsionadas pelo Movimento Negro, têm incentivado a busca pela tradição cultural negra, uma preocupação que, em vários casos, não está presente no cotidiano dos grupos. O desenvolvimento de ações que buscam valorizar a cultura negra pode ser uma tentativa de a Prefeitura tornar relevante os elementos culturais negros na construção da identidade belo-horizontina. Ações que refletem o discurso do Movimento Negro, que pauta seu debate na ancestralidade, na herança cultural perpassada no decorrer dos tempos, que deve ser mantida viva nos tempos atuais (LOTT, 2005).

\section{Ressonância junto ao público?}

A religiosidade afro-brasileira sempre se fez presente no território belohorizontino, embora sua trajetória seja constituída à margem da história oficial da cidade, bem como do circuito dos estudos sobre o tema no Brasil. Conforme apresentado neste artigo, os festejos dedicados a Nossa Senhora do Rosário remontam ao século XIX, a umbanda começou a ser praticada na década de 1930 e, nos anos 1960, chegou o candomblé, vindo da Bahia e também do Rio de Janeiro. As manifestações de matriz africana, como dito anteriormente, mantêm uma articulação entre elas, que advém da forma como foram se constituindo ao longo do tempo.

Quando de sua formação na Bahia, em meados do século XIX, o candomblé era um espaço onde se mantinham os costumes africanos. Porém, quando veio para Minas, passou a apresentar um novo perfil. Os umbandistas buscavam o culto às divindades africanas pois acreditavam que os rituais do candomblé poderiam complementar os trabalhos já realizados nos terreiros da capital. Ao contrário do que

${ }^{17}$ Citando Stephen Greenblatt, Gonçalves define ressonância como o poder de um objeto exposto atingir um universo mais amplo, de evocar no espectador as forças culturais complexas e dinâmicas que o originaram e das quais, do ponto de vista do espectador, ele é o representante.

Latitude, Vol. 4, n², pp. 25-42, 2010. 
Ações do poder público e a prática da umbanda, candomblé e congado: Reflexões sobre a construção de patrimônios culturais

aconteceu na Bahia, em Belo Horizonte os espaços de culto às divindades africanas não foram criados, em sua maioria, como estratégia de resistência. Eles surgiram, inicialmente, como uma forma de apoio aos serviços prestados pelos terreiros de umbanda aos fiéis e adeptos.

As práticas religiosas afro-brasileiras foram se articulando e constituindo seu espaço na cidade e, somente a partir da década de 1980, é que passam a contar com o apoio do Movimento Negro, que teve, certamente, um papel importante no desenvolvimento de ações do governo municipal voltadas para o congado, a umbanda e o candomblé. No entanto, é necessário refletir sobre a forma como essas ações estão sendo construídas, verificar se há ressonância junto ao público, nos termos de Gonçalves (2005).

As reflexões iniciais sobre a questão, com base na bibliografia acerca do tema, apontam que o envolvimento do movimento negro com as manifestações religiosas foi posterior à conformação do movimento religioso. Dado o estado inicial da pesquisa, ainda não é possível apontar em que aspectos as políticas desenvolvidas pela Prefeitura influenciam a prática dessas manifestações, ou se a preocupação com a preservação da cultura negra é um dos elementos que motivam a participação nos cultos de umbanda e candomblé e nos festejos do congado. A partir da literatura consultada, é possível afirmar que nem sempre a forma como o poder público busca preservar as manifestações afro-brasileiras em Belo Horizonte condiz com a maneira como esse patrimônio é construído por seus praticantes. No entanto, nesta pesquisa ainda não foi realizado o trabalho de campo, necessário para que tal questão seja verificada.

\section{Referências bibliográficas}

ABREU, Regina. Quando o campo é o patrimônio: notas sobre a participação de antropólogos nas questões do patrimônio. Sociedade e Cultura, Goiânia, v. 8, n. 2, pp. 37-52, jul/dez 2005.

BARRETO, Abílio. Belo Horizonte: memória histórica e descritiva - história antiga. Belo Horizonte: Fundação João Pinheiro, Centro de Estudos Históricos e Culturais, 1995.

BASTIDE, Roger. As religiões africanas no Brasil. Contribuição a uma sociologia das interpenetrações de civilizações. São Paulo: Livraria Pioneira Editora, Editora da USP, 1971. 
Mariana Ramos de Morais

BELO HORIZONTE. Heranças do tempo: tradições afro-brasileiras em Belo Horizonte. PONTES, Ana Cristina; MORAIS, Fernanda Emília de (Orgs.). Belo Horizonte: Fundação Municipal de Cultura, 2006.

BELO HORIZONTE. Plano Municipal de Promoção da Igualdade Racial. Belo Horizonte: Prefeitura de Belo Horizonte, 2009.

CAMARGO, Cândido Procópio Ferreira de. Kardecismo e umbanda: uma interpretação sociológica. São Paulo: Livraria Pioneira Editora, 1961.

CAPONE, Stefania. A busca da África no candomblé: tradição e poder no Brasil. Rio de Janeiro: Contra Capa Livraria/Pallas, 2004.

CARDOSO, Alexandre. Dimensões básicas da religiosidade belo-horizontina. Estudos Avançados, São Paulo, ano 18, n.52, pp. 63-75, 2004.

DANTAS, Beatriz Góis. Vovó nagô e papai branco: usos e abusos da África no Brasil. Rio de Janeiro: Edições Graal, 1988.

DOUGLAS, Mary. Pureza e perigo. São Paulo: Perspectiva, 1976.

FARIAS, Edson. (Re)tradicionalização ou (re)significações de tradições? In: TEIXEIRA, João Gabriel L.C; GARCIA, Marcus Vinicius Carvalho; GUSMÃO, Rita. (Orgs.). Patrimônio imaterial, performance cultural e (re)tradicionalização. Brasília: UnB, 2004.

GONÇALVES, José Reginaldo dos Santos. A retórica da perda: os discursos do patrimônio cultural no Brasil. Rio de Janeiro: Ed. UFRJ/Iphan, 1996.

GONÇALVES, José Reginaldo dos Santos. Ressonância, materialidade e subjetividade: as culturas como patrimônios. Horizontes Antropológicos, Porto Alegre, ano 11, n. 23, pp. 15-36, jan/jun 2005.

HOBSBAWM, Eric; RANGER, Terence. A invenção das tradições. Rio de Janeiro: Paz e Terra, 1984.

JACCOUD, Luciana. (Org.) A construção de uma política de promoção da igualdade racial. Brasília: Ipea, 2009.

LEONEL, Guilherme Guimarães. Entre a cruz e os tambores: conflitos e tensões nas festas do reinado (Divinópolis - MG). Dissertação de mestrado. Programa de Pós- 
Ações do poder público e a prática da umbanda, candomblé e congado: Reflexões sobre a construção de patrimônios culturais

Graduação em Ciências Sociais, Pontifícia Universidade Católica de Minas Gerais, Belo Horizonte, 2009.

LOTT, Wanessa Pires. Patrimônio cultural na cidade de Belo Horizonte: o caso da "Irmandade de Nossa Senhora do Rosário do Jatobá" e do Terreiro de Candomblé "Ilê Wopo Olojukan". Dissertação de Mestrado. Programa de Pós-Graduação em Ciências Sociais, Pontifícia Universidade Católica de Minas Gerais, Belo Horizonte, 2005.

LUCAS, Glaura. Os sons do Rosário. O congado mineiro dos Arturos e Jatobá. Belo Horizonte, Editora UFMG, 2002.

MAGNANI, José Guilherme Cantor. Umbanda. São Paulo: Editora Ática, 1986.

MORAIS, Mariana Ramos de. Nas teias do sagrado: registros da religiosidade afrobrasileira em Belo Horizonte. Belo Horizonte: Espaço Ampliar, 2010.

MORAIS, Mariana Ramos de. O candomblé na metrópole: a construção da identidade em dois terreiros de Belo Horizonte. Dissertação de Mestrado. Programa de PósGraduação em Ciências Sociais, Pontifícia Universidade Católica de Minas Gerais, Belo Horizonte, 2006.

NEGRÃO, Lísias Nogueira. Entre a cruz e a encruzilhada: formação do campo umbandista em São Paulo. São Paulo: Editora da Universidade de São Paulo, 1996.

PONTES, Ana Cristina. O candomblé em Belo Horizonte. In: BELO HORIZONTE. Heranças do tempo: tradições afro-brasileiras em Belo Horizonte. PONTES, Ana Cristina; MORAIS, Fernanda Emília de (Orgs.). Belo Horizonte: Fundação Municipal de Cultura, 2006.

PRANDI, Reginaldo. Segredos guardados: os orixás na alma brasileira. São Paulo: Companhia das Letras, 2005.

PRANDI, Reginaldo. Converter indivíduos, mudar culturas. Tempo Social, São Paulo, USP, v. 20, n. 2, pp. 155-172, 2008.

SANCHIS, Pierre. As tramas sincréticas da história. Revista Brasileira de Ciências Sociais, São Paulo, n. 28, pp. 123-138, 1995.

SANCHIS, Pierre. As religiões dos brasileiros. Horizonte, Belo Horizonte, v.1, n.2, pp.28-43, 2os sem, 1997. 
SANCHIS, Pierre. Religiões, religião... Alguns problemas do sincretismo no campo religioso brasileiro. In: SANCHIS, Pierre (Org). Fiéis e cidadãos: percursos de sincretismo no Brasil. Rio de Janeiro: Ed. Uerj, 2001.

SANTOS, Erisvaldo Pereira dos. A afirmação identitária, espaços e símbolos da religiosidade de matriz africana em Belo Horizonte. Anais do Museu Histórico Nacional - História e Patrimônio, Rio de Janeiro, v. 40, pp. 237-260, 2008.

SANTOS, Jocélio Teles dos. O poder da cultura e a cultura no poder: a disputa simbólica da herança cultural negra no Brasil. Salvador: Edufba, 2005.

THEODORO, Mário. As políticas públicas e a desigualdade racial: 120 anos após a abolição. Brasília: Ipea, 2008.

VELHO, Gilberto. Patrimônio, negociação e conflito. Mana, Rio de Janeiro, v. 12, n.1, pp. 237-248, abr. 2006.

VILARINO, Marcelo de Andrade. Festas, cortejos, procissões: tradição e modernidade no congado belo-horizontino. Dissertação de mestrado. Programa de Pós-Graduação em Ciência da Religião, Instituto de Ciências Humanas, Universidade Federal de Juiz de Fora, Juiz de Fora, 2007. 